\title{
Programa Jovem de Futuro: uma tecnologia educacional do terceiro setor
}

\author{
Youth with a Future Program: a third sector educational technology
}

Programa Joven de Futuro: una tecnología educativa del tercer sector

\author{
Maria Aparecida Canale Balduino ${ }^{1}$ \\ Recebido em 26/07/2018; revisado e aprovado em 14/04/2019; aceito em 10/05/2019 \\ DOI: http://dx.doi.org/10.20435/inter.v21i2.2098
}

Resumo: Este artigo tem como foco a discussão que surge nas relações entre o público e o privado na educação e, de maneira mais específica, as implicações que a tecnologia educacional do Programa Jovem de Futuro (PJF), apresentada, criada e desenvolvida pelo Instituto Unibanco (IU), gera na gestão das escolas públicas. A tecnologia é pré-qualificada no Guia de Tecnologias Educacionais do Ministério da Educação (MEC) e efetiva-se por meio de parcerias realizadas com o MEC, os governos dos estados do Ceará, Goiás, Mato Grosso do Sul, Pará e Piauí e o instituto, no âmbito do Programa Ensino Médio Inovador/Jovem de Futuro, para a gestão de escolas de Ensino Médio. A pesquisa situa-se no contexto da redefinição do papel do Estado, em decorrência de uma crise estrutural do capital sob a ótica da ideologia neoliberal, que, como forma de superá-la, sob o argumento de que aquilo que está em crise é o Estado, e não o capital, indica como saída a reforma do Estado mediante a redução de seu papel, de modo mais específico na execução de políticas sociais, entre elas as educacionais. A metodologia da pesquisa tem por base um levantamento bibliográfico nos documentos do Instituto Unibanco e em seus materiais editoriais impressos. Por meio dos materiais, pode-se identificar que o PJF emprega a lógica de mercado nas escolas públicas de Ensino Médio e induz a responsabilização das escolas pelos resultados, o que incorpora alterações nas suas propostas pedagógicas e, assim, compromete a autonomia da gestão escolar, ferindo o princípio da gestão democrática.

Palavras-chave: terceiro setor; parceria público-privada; Programa Jovem de Futuro.

Abstract: This article focuses on the discussion that arises in the relationship between the public and the private in education and, more specifically, the implications that the educational technology of the Youth with a Future Program (PJF), presented, created and developed by the Unibanco Institute (IU), generates in the management of public schools. The technology is pre-qualified in the Educational Technologies Guide of the Ministry of Education (MEC) and is effective through partnerships with the MEC, the governments of the states of Ceará, Goiás, Mato Grosso do Sul, Pará and Piauí and the institute, within the framework of the High School Program Innovative/Youth with a Future, for the management of high schools. The research takes place in the context of the State role redefinition, as a result of a structural crisis of the capital from the perspective of neoliberal ideology, which, as a way of overcoming it, under the argument that what is in crisis is the State, and not the capital, indicates as a way out the State reform by reducing its role, more specifically in the execution of social policies, among them, the educational ones. The methodology of the research is based on a bibliographic survey in the documents of the Unibanco Institute and its printed editorial materials. Through the materials, it can be identified that the PJF employs the market logic in public high schools and induces the schools to be accountable for the results, which incorporate changes in their pedagogical proposals and, thus, compromise the school management autonomy, violating the principle of democratic management.

Keywords: third sector; public-private partnership; Youth with a Future Program.

Resumen: Este artículo tiene como foco la discusión que surge en las relaciones entre lo público y lo privado en la educación y, de manera más específica, las implicaciones que la tecnología educativa del Programa Joven de Futuro (PJF), presentada, creada y desarrollada por el Instituto Unibanco (IU), genera en la gestión de las escuelas públicas. La tecnología es precalificada en la Guía de Tecnologías Educativas del Ministerio de Educación (MEC) y se efectúa por medio de alianzas realizadas con el MEC, los gobiernos de los estados de Ceará, Goiás, Mato Grosso do Sul, Pará y Piauí y el instituto, en el marco del Programa Enseñanza Media Innovadora/Joven de Futuro, para la gestión de escuelas de Enseñanza Media. La investigación se sitúa en el contexto de la redefinición del papel del Estado, como consecuencia de una crisis estructural del capital desde la perspectiva de la ideología neoliberal, que, como forma de superarla, bajo el argumento de que quien está en crisis es el Estado, y no el capital, indica la reforma del Estado como salida, mediante la reducción de su papel, de modo más específico en la ejecución de políticas sociales, entre ellas las educativas. La metodología de la investigación tiene como base una búsqueda bibliográfica en los documentos del Instituto Unibanco y

\footnotetext{
${ }^{1}$ Universidade Católica Dom Bosco (UCDB), Campo Grande, Mato Grosso do Sul, Brasil.
} 
en sus materiales editoriales impresos. Por medio de los materiales, se puede identificar que el PJF emplea la lógica de mercado en las escuelas públicas de Enseñanza Media e induce la responsabilización de las escuelas por los resultados, lo que incorpora alteraciones en sus propuestas pedagógicas y, así, compromete la autonomía de la gestión escolar, perjudicando el principio de la gestión democrática.

Palabras clave: tercer sector; colaboración público-privada; Programa Joven de Futuro.

\section{INTRODUÇÃO}

A presente pesquisa analisa as implicações do Programa Jovem de Futuro (PJF) para a autonomia da gestão das escolas públicas de Ensino Médio, no âmbito da parceria entre o setor público, representado pelas redes estaduais de ensino, e o privado, pelo Instituto Unibanco (IU), assim como aborda as estratégias políticas que viabilizaram o crescimento das parcerias entre o setor público e o setor privado no campo educacional.

O enfoque teórico metodológico desta pesquisa utilizou como base um levantamento bibliográfico nos documentos do Instituto Unibanco, disponíveis em seu site, bem como de seus materiais editoriais impressos, como o "Cardápio de Metodologias - propostas pedagógicas para aplicação em escolas públicas de Ensino Médio" (2011); o “Cardápio de Metodologias Jovem de Futuro - estratégias para implementação do projeto aplicadas a gestores, professores e alunos" (2011); os relatórios de atividades do Instituto Unibanco, publicados entre 2009 e 2012; os "Manuais para a Secretaria de Educação - Jovem de Futuro" (2012); e a legislação educacional brasileira.

A pesquisa situa-se no contexto de redefinição do papel do Estado, em decorrência da crise estrutural do capital, perceptível a partir da década de 1970 (MÉSZAROS, 2011). Como forma de superá-la, a ideologia neoliberal, sob o argumento de que o Estado é que está em crise, e não o capital, indica como saída a reforma do Estado mediante a redução do seu papel, de modo mais específico na execução de políticas sociais, entre elas as educacionais; desta forma, o Estado transfere para o mercado a responsabilidade de superar suas insuficiências (PERONI, 2012).

Surge neste cenário como proposta alternativa ao neoliberalismo a Terceira Via, que sugere como forma de superação o repasse de atividades de responsabilidade do Estado para a sociedade civil sem fins lucrativos, especialmente para o terceiro setor, redefinindo o papel do Estado por meio de um novo modelo de relação com a sociedade civil, principalmente no que tange às políticas sociais, que se efetivariam por meio das denominadas parcerias público-privadas.

\section{AS NOVAS CONFIGURAÇÕES ENTRE O PÚBLICO E O PRIVADO NO CONTEXTO BRASILEIRO}

No Brasil, a configuração desse movimento está expressa no Plano Diretor da Reforma do Aparelho do Estado (PDRAE), apresentado no governo Fernando Henrique Cardoso (1995-2003), que induz o crescimento de parcerias do setor público com o setor privado, de modo que o setor privado passou a influenciar, cada vez mais, as políticas públicas em todos os níveis.

Assim, no Brasil, o PDRAE apresentou a reforma como caminho para superação da crise que o Estado sofria e, em seu conteúdo, propôs que o papel do Estado fosse redefinido, assim como deixasse "[...] de ser o responsável direto pelo desenvolvimento econômico e social pela via da produção de bens e serviços para fortalecer-se na função de promotor e regulador desse desenvolvimento" (BRASIL, 1995, p. 17). 
O documento também apresentou três estratégias necessárias para que a crise pudesse ser superada: a privatização, a publicização e a terceirização, o que acabou por introduzir, por meio de parcerias público-privadas (PPPs), contratos de gestão ou termos de cooperação, isto é, formas de privatização nas políticas públicas, formando o que se intitula de "quase-mercado", pois, apesar de a propriedade permanecer na esfera pública, o método de gestão utilizado passa a ser o do setor privado.

$\mathrm{Na}$ atual conjuntura do capitalismo, as reformas que surgiram na gestão da administração pública e no setor da educação pública foram no sentido de realizar alterações nas estruturas das escolas públicas a partir de mudanças administrativas e pedagógicas, mediante a implantação de uma gestão pedagógica que adotasse o modelo de gestão gerencial utilizado pelo setor privado.

A propagação das parcerias entre o setor público e o setor privado voltadas para o campo educacional merece ser examinada de maneira cuidadosa e, em certo grau, investigada com alguma preocupação, pois, desde a adoção das parcerias público-privadas como estratégia política para superação da crise do capital, o rápido crescimento delas no setor educacional inclui cada vez mais sujeitos pertencentes ao setor privado em atividades de políticas públicas que abrangem áreas tradicionais nas redes de ensino público, por exemplo, na gestão escolar, transformando-as em "uma indústria de serviços de educação a ser governada, como parte da construção de uma sociedade de mercado" (ROBERTSON; VERGER, 2012, 1.135).

Para Lima (2013, p. 178-9), a privatização é responsável pelo desgaste do Estado para com suas responsabilidades em favor da concessão de políticas públicas para o setor privado, favorecendo as parcerias, as quais, como no caso da educação pública, interferem na construção e no desenvolvimento das redes de ensino, que deixam de ser públicas e se tornam híbridas, apoiadas nas parcerias público-privadas, de forma que a gestão das escolas passa a ser regida e gerenciada por diretrizes de instituições privadas.

Amplia esta discussão Frigotto (2011), ao afirmar que passa a ser incluída na educação a necessidade da formação e do desenvolvimento de estudantes em conformidade com as demandas do mercado, sob a justificativa da expansão do setor privado e do terceiro setor como mediadores de produtividade do mercado.

O setor privado imprime em seus programas voltados para políticas públicas um discurso de qualidade por meio de uma gestão que foca em resultados, mas que não considera a economia, a cultura, o desenvolvimento, os recursos e a qualidade de vida nos locais em que são estabelecidos e desenvolvidos.

Os empresários brasileiros, desde o início dos anos 1990, organizam fóruns e documentos manifestando interesse em construir programas educacionais. Sob essa ótica, sugerem reformar as escolas públicas e a educação mediante a introdução do modelo de eficácia utilizado pela administração, a fim de alcançar as demandas exigidas pelo capital e formar novos trabalhadores com conhecimento em competências organizacionais e tecnológicas.

No Brasil, o movimento de protagonismo do setor privado em políticas educacionais pode ser observado por meio do Movimento Todos pela Educação (TPE), fundado no ano de 2006 e que apresentou como plano de atuação a inclusão de um sistema de monitoramento e análise dos indicadores educacionais oficiais, passando a definir a agenda da educação do país por meio de avaliações de resultados.

Salienta-se ainda a relação que surge entre o TPE e o Plano de Desenvolvimento da Educação (PDE) no que tange ao Guia de Tecnologias do Ministério da Educação (MEC), que se configura 
como um meio de os empresários venderem suas tecnologias educacionais e concorrerem diretamente no sistema público de educação (PERONI, 2012); assim, conforme afirmam Robertson e Verger (2012, p. 1.149), a influência que o setor privado, por meio de PPPs, passa a exercer no âmbito da educação pública permite "seu rápido avanço, dado que o setor privado está agora profundamente enraizado no coração dos serviços públicos educacionais, em todos os níveis, desde a política e a pesquisa até a aprendizagem nas salas de aula" (ROBERTSON; VERGER, 2012, p. 1.149).

Nesse contexto, situa-se o Programa Jovem de Futuro (PJF), uma proposta de gestão para as escolas públicas do Ensino Médio, concebida e desenvolvida como uma metodologia educacional pelo Instituto Unibanco (IU), uma instituição pertencente ao terceiro setor.

\section{UMA PROPOSTA DO TERCEIRO SETOR PARA A GESTÃO DA ESCOLA PÚBLICA}

O Instituto Unibanco foi fundado no ano de 1982, com o objetivo de promover, criar, produzir e desenvolver os investimentos sociais do banco², e se caracteriza como uma instituição do terceiro setor que integra o movimento denominado Todos pela Educação.

Shiroma, Garcia e Campos (2011, p. 233-4) afirmam que o TPE foi "criado por um grupo de intelectuais orgânicos do capital", a partir da premissa de que o terceiro setor deveria atuar junto ao Estado, promovendo eventos que propunham à sociedade civil e aos sindicatos acordos voltados para a educação. Desse modo, "os empresários se antecipam e pautam a agenda governamental: reafirmam o papel do Estado redefinindo, no entanto, o sentido e o significado da educação pública" (SHIROMA; GARCIA; CAMPOS, 2011, p. 226) e, ainda segundo as autoras, o TPE "visa mobilizar a iniciativa privada e organizações sociais do chamado 'terceiro setor' para atuar de forma convergente, complementar e sinérgica com o Estado no provimento das políticas públicas".

Ressalte-se que ações por parte do setor empresarial na educação não são um fato novo no decorrer da história educacional. O setor empresarial sempre se empenhou para definir sua área de atuação política e buscou traduzir, por meio de leis e espaços exclusivos, seus interesses e objetivos para com a educação (NEVES, 2000; RODRIGUES, 1998). O IU afirma ainda que, durante alguns anos, dedicou-se a apoiar diversos projetos de diferentes instituições e áreas, porém, a partir de 2002, buscou redirecionar sua forma de atuação e se voltou para a educação, quando passou a desenvolver os próprios projetos (INSTITUTO UNIBANCO, 2009).

A proposta denominada Jovem de Futuro, segundo o Relatório de Atividades de 2011 do IU, foi apresentada no ano de 2006, como forma de um projeto que teria a duração de três anos - o correspondente a um ciclo e período de duração do Ensino Médio - com foco na Gestão Escolar para Resultados, com o argumento de ser o modo pelo qual as escolas públicas de Ensino Médio alcançariam uma melhoria na qualidade da educação pública (INSTITUTO UNIBANCO, 2011).

No ano de 2007, o IU concebeu e implantou de forma experimental o Projeto Jovem de Futuro em três escolas paulistanas. No ano seguinte (2008), expandiu-se e o IU formalizou a proposta como projeto-piloto em 20 instituições de ensino de Minas Gerais e 22 do Rio Grande

\footnotetext{
${ }^{2}$ A partir do ano de 2008, por meio de uma fusão, passou a incorporar o grupo Banco Itaú, um banco de varejo e múltiplo, e tornou-se o maior banco da América do Sul. Informações produzidas pelo instituto e obtidas no site. Disponível em: www.institutounibanco.org.br. Acesso em: 2 maio 2017.
} 
do Sul. Em 2009, ampliou para mais 41 escolas do estado de São Paulo, sendo 21 na região metropolitana da capital e 20 em municípios da região do Vale do Paraíba, e, no ano de 2010, conforme o Relatório de Atividades do mesmo ano, após um período de três anos, "o Projeto Jovem de Futuro encerrou um ciclo completo de implantação", contribuindo para os subsídios de validação do projeto e sua posterior disseminação e aplicação em larga escala ${ }^{3}$ (INSTITUTO UNIBANCO, 2010, p. 33).

Para implementar o PJF nas escolas de Ensino Médio, o IU organizou como uma das modalidades de ação um material denominado "Cardápio de Metodologias - Propostas pedagógicas para aplicação em escolas públicas de Ensino Médio" - conforme o instituto, a fim de proporcionar um melhor e maior entendimento de cada proposta educacional formulada e ainda oferecer "um importante conjunto de instrumentos orientados a consolidar uma nova cultura de gestão" (INSTITUTO UNIBANCO, 2010, s.p.).

As metodologias trazidas nos "Cardápios de Metodologias" são divididas em imprescindíveis e opcionais e têm como objetivo, segundo o IU, "contribuir para a melhoria do desempenho do aluno e a redução da evasão escolar" (INSTITUTO UNIBANCO, 2010). Quando o IU define o "Cardápio de Metodologias" como estratégias para implementação de projetos, indica, nos termos em que se apresenta, uma linguagem mercadológica, pois, na lógica empresarial, estratégias "são cursos de ação que procuram viabilizar a realização de objetivos organizacionais que traduzem o aproveitamento de oportunidades e o enfrentamento de ameaças" (MAXIMIANO, 2005, p. 361).

Como define a Teoria da Administração, estratégias constituem-se em "uma etapa em cadeia de meios e fins. Para colocá-la em prática é necessário elaborar e executar planos funcionais políticos e planos operacionais" (MAXIMIANO, 2005, p. 361). Com base nesse conceito, nota-se que o IU utiliza os mecanismos aplicados no mercado em seus projetos voltados para a gestão da escola pública, pois associa impacto pedagógico ao alcance das metas, uma estratégia "que combina a aplicação dos instrumentos imprescindíveis com aqueles considerados opcionais" (INSTITUTO UNIBANCO, 2011, p. 22).

Destaca-se que, no ano de 2009, o Projeto Jovem de Futuro foi inserido no Guia de Tecnologias ${ }^{4}$, do MEC, que compõe o PDE e o Plano de Metas Todos pela Educação lançado no segundo mandato do governo Luiz Inácio Lula da Silva (2007-2010).

Segundo o MEC, a proposta é oferecer aos gestores educacionais ferramentas que os auxiliem na aquisição de materiais e de tecnologias para uso nas escolas públicas brasileiras

\footnotetext{
${ }^{3} \mathrm{O} I \mathrm{IU}$ classifica as escolas que aderem ao projeto como pertencentes ao grupo denominado de tratamento, que desenvolverá de modo efetivo o projeto, ou ao grupo intitulado de controle, que não atua diretamente na ação, mas serve de indicador para avaliar a evolução desenvolvida pela metodologia e se compromete a realizar todas as avaliações de desempenho das quais o IU utiliza como parâmetro; a avaliação de impacto realiza-se por meio de comparação entre os resultados dos dois grupos (INSTITUTO UNIBANCO, 2010).

${ }^{4}$ O Guia de Tecnologias está separado por seis blocos e o Projeto Jovem de Futuro é integrado ao bloco de Gestão da Educação. De acordo com o Guia de 2009, tecnologias educacionais devem ser entendidas como as práticas, metodologias ou técnicas de ensino que podem ser criadas ou já estar em uso por redes (públicas ou privadas) e estabelecimentos de ensino que "apresentem condições de promover a qualidade da Educação Básica em todas as suas etapas (Educação Infantil, Ensino Fundamental e Ensino Médio) e modalidades" (BRASIL, 2009, p. 13). Nesse sentido, o MEC lança os editais de "Pré-Qualificação de Tecnologias Educacionais que Promovam a Qualidade da Educação Básica" e convoca os interessados a apresentar tecnologias educacionais que apresentem condições de favorecer essa qualidade em todas as suas etapas (Educação Infantil, Ensino Fundamental e Ensino Médio) e modalidades (BRASIL, 2009, p. 15). Segundo a apresentação do Guia de Tecnologias Educacionais o MEC assinala que o objetivo principal da proposta é alcançar uma educação pública de qualidade.
} 
(BRASIL, 2011) e, utilizando as palavras de Peroni (2011, p. 37), é preciso perguntar: "o que significa o sistema público abrir mão das suas prerrogativas de ofertas de educação pública de qualidade e comprar um produto pronto [...]?".

Ainda nesse sentido, Peroni et al. (2012, p. 40-1) destacam que o propósito, nesse questionamento, não é "[...] desconsiderar e desqualificar a importância da política desenvolvida pelo Ministério da Educação que propõe regulamentar, através da certificação e validação, a qualidade dessas tecnologias". Concorda-se com os autores, principalmente quando criticam o incentivo à parceria (com o setor privado em categorias estratégicas, como currículo e trabalho docente, e ao fato de "[...] entregá-las à lógica do mercado".

Ainda conforme Peroni (2012, p. 31), quando o MEC fala em "[...] pré-qualificar as tecnologias educacionais do setor privado em vez de criar políticas públicas que contemplem as demandas da educação pública brasileira", podem ser indicados dois fatores: que no Brasil inexistem políticas públicas, e o estado brasileiro "através do MEC está em sintonia com a ideologia do empresário, subordinando a educação à lógica de mercado"; que o Estado, ao adotar e qualificar tecnologias e serviços desenvolvidos e ofertados pelo setor privado, deixa de realizar investimentos na educação pública e repassa os encargos e as responsabilidades ao setor privado.

É importante mencionar que, no ano de 2009, o Governo Federal concebeu e instituiu uma proposta para o Ensino Médio: o Programa Ensino Médio Inovador (ProEMI), sendo que, no ano de 2012, integrou-se ao Projeto Jovem de Futuro ${ }^{5}$ e passou a denominar-se Programa Ensino Médio Inovador/Jovem de Futuro (ProEMI/Jovem de Futuro).

Convém esclarecer, utilizando as palavras do instituto, que, "além de se associar à proposta educativa do Instituto Unibanco, o MEC assumiu a responsabilidade por repassar os recursos para o desenvolvimento da ação diretamente às escolas atendidas, por meio do Programa Dinheiro Direto na Escola (PDDE)" (INSTITUTO UNIBANCO, 2011, p. 24).

Chama-se a atenção aqui para alguns aspectos, no mínimo, intrigantes. Em primeiro lugar, questiona-se a junção dos programas, uma vez que são propostas diferentes ou mesmo antagônicas. O ProEMI é um programa oriundo do MEC voltado para inovação curricular, com foco no Ensino Médio integrado e integral, enquanto o Projeto Jovem de Futuro, de iniciativa privada, fundamenta-se na concepção de Gestão Escolar para Resultados, acarretando uma contradição política, na medida em que um projeto de iniciativa privada é pré-qualificado em uma chamada do setor público, no caso do MEC, antes mesmo de encerrar o período de validação, para aplicação em larga escala nos sistemas de ensino. Nesse sentido, a dimensão ética dessa ação merece atenção, pois, conforme a análise de Freitas (2012, p. 386):

Praticar política pública sem evidência empírica, mais do que gastar dinheiro inadequadamente, caracteriza violação da ética já que não se devem fazer experimentos sociais com ideias pouco consolidadas pela evidência empírica disponível. A avaliação mexe com a vida de alunos, professores, pais e gestores.

\footnotetext{
${ }^{5}$ A parceria foi oficializada em 14 de fevereiro de 2012, com a assinatura do termo de cooperação técnica do Instituto Unibanco. A Secretaria de Assuntos Estratégicos (SAE) do Governo Federal, que viabilizou a execução do ProEMI/PJF, segundo o IU, "conta com um sistema de governança própria e metas bem estabelecidas" (INSTITUTO UNIBANCO, 2012, p. 21). O ministro da Educação à época, Aloizio Mercadante (24 de janeiro de 2012 a 3 de fevereiro de 2014), manifestou-se da seguinte forma quanto à integração do ProEMI com o PJF: "A escola tem que se modernizar, buscar entender um pouco a juventude, essa inquietação, essa vontade de participar [...]". E explicou que os dois programas "são para nós um caminho bastante importante para avaliar essas metodologias (INSTITUTO UNIBANCO, 2012, p. 21-2).
} 
O segundo aspecto é o fato de se aplicarem recursos do PDDE, antes utilizados para financiar o ProEMI, que agora passam a ser empregados para financiar um programa de gestão privada. Após a inserção do PJF no Guia de Tecnologias do MEC, no ano de 2011, o IU iniciou o processo de transferência da tecnologia às redes estaduais de ensino dos estados do Ceará, Goiás, Mato Grosso do Sul, Pará e Piauí, que aderiram ao projeto. Diante disso, expande-se para os estados que não participaram da fase de validação e que aderiram à parceria; como informa o IU, o ano de 2012 "marca o início da expansão do projeto Jovem de Futuro, época em que foi constituído, em parceria com o Programa Ensino Médio Inovador, do MEC, o ProEMI/PJF, tornando-se a principal política pública de Ensino Médio das Secretarias Estaduais de Educação do Estado do Ceará, Goiás, Mato Grosso do Sul, Pará, Piauí" (INSTITUTO UNIBANCO, 2012, p. 12).

Conforme afirma o IU, o primeiro passo para execução do projeto é oferecer um treinamento por meio de um curso de Gestão Escolar para Resultados aos representantes (supervisores da Secretaria de Educação, grupos gestores escolhidos pelas escolas e equipe técnica) de todos os estados que adotaram o projeto, para experimentar, na prática, as ferramentas que a metodologia proporciona para conduzir o primeiro ciclo nas escolas.

Para o instituto, a prática de Gestão Escolar para Resultados (GEpR), em que o projeto Jovem de Futuro se fundamenta, referencia-se no ideário do economista Peter Drucker, que propõe sistemas de Administração por Objetivos (APO) e, conforme Maximiano (2005), a base na aplicação é a prática do processo de planejar, organizar, executar e controlar.

O IU considera o GEpR um “Modelo de ação que visa assegurar os objetivos propostos pelo Projeto Jovem de Futuro, integrando ferramentas e recursos culturais, conceituais e operacionais no processo de gestão, com vistas à melhoria de resultados" (INSTITUTO UNIBANCO, 2010, p. 18).

Para tanto, entende-se que a implementação da gestão proposta "envolve uma mudança cultural" que impõe o dever de criar estratégias que alteram métodos como "gestão de recursos humanos, materiais e financeiros, fomentando uma nova cultura organizacional" e vincula-se o sucesso desse modelo de gestão a "um sistema de incentivos e sanções positivas e negativas" (INSTITUTO UNIBANCO, 2010, p. 18). Assim, a gestão com foco em resultados efetiva-se por meio de um Plano de Ação por escola, que se caracteriza, conforme afirma o IU, como o meio pelo qual "uniformiza os sistemas de avaliação, além de alinhar o projeto político pedagógico (PPP) e outros programas existentes, orientando a tomada de decisões do grupo gestor para a conquista dos resultados esperados com a ação" (INSTITUTO UNIBANCO, 2011, p. 17).

A proposta de gestão do IU se organiza, portanto, por meio da separação entre planejamento e execução, assim como divide e fragmenta a execução do trabalho da escola, reproduzindo a escala hierárquica utilizada pela lógica do modelo empresarial (MONTEIRO, 2013). Para isso, o IU trabalha com o conceito de GEpR, cujo pressuposto é de "que não existe organização com capacidade de produzir resultados de qualidade sem uma gestão eficiente e eficaz" (INSTITUTO UNIBANCO, 2012, p. 15).

Em fevereiro de 2012, quando o Programa Jovem de Futuro passou a ser disseminado e começou a transferir a tecnologia, o IU publicou a primeira edição dos "Manuais da Secretaria de Educação", compostos por três partes assim intituladas: "Manual de pré-implantação", "Manual de implantação" e "Manual de gestão" (INSTITUTO UNIBANCO, 2012). Esse material é entendido como ferramenta utilizada pela gestão empresarial, pois tem por finalidade estabelecer regulamentos, normas, atividades, ou ainda um sistema, de modo a conduzir os gestores, supervisores, diretores e professores, conforme afirma o IU em seu material editorial (INSTITUTO UNIBANCO, 2012). 
O "Manual de pré-implantação", primeira parte do documento elaborado pelo IU para as Secretarias de Educação que recebem o Programa Jovem de Futuro, apresenta, em forma de processos, as ações a serem desenvolvidas pelo responsável pelo Programa na Secretaria de Educação do estado que o receber. Já o "Manual de Gestão" apresenta os conteúdos sob a forma de fluxogramas, em que o IU mostra o processo de gestão semelhante a um relatório de empresa, fazendo uso de termos comumente utilizados pelo mercado, com a intenção de formar estudantes e gestores escolares. Salienta-se aqui que a linguagem de mercado, ferramenta que, conforme Araújo (2009, p. 34), tem sua origem na Organização Sistemas e Métodos (OSM), insere-se em abordagens contemporâneas da análise e gestão de processos.

Segundo essa lógica, o uso de fluxogramas é uma forma de controle das atividades por meio de ações padronizadas para a minimização de erros. O conceito da OSM de organizar, sistematizar e aplicar métodos para uma proposta de gestão remete às raízes do Taylorismo, que tem em seus princípios a padronização de ações para uma gestão eficaz. Conforme Araújo (2009), nesse processo desenvolvem-se também manuais que se constituem instrumentos de consulta permanente de como devem ser pautadas as rotinas de trabalho. Os manuais fornecidos pelo IU têm como propósito o alcance de resultados, fato que se torna claro quando o instituto a alteração no currículo e a formação de gestores e professores.

O uso dos manuais como os fornecidos pelo IU, assim como o "Cardápio de Metodologias", ressalta o caráter tecnicista, aliado ao entendimento de que o setor público não tem qualidade e que o privado, portanto, é eficiente. Projetos voltados para a educação pública como o Jovem de Futuro do IU nos levam à análise de Freitas (2012, p. 383), de que a ênfase em gestão e a adição de tecnologia são características da forma como os empresários fazem modificações no âmbito da produção, porém "a lógica é transferida para o campo da educação". Ainda de acordo com Freitas (2012), essa forma de pensar a educação é definida por Saviani, nos anos 1980, como "pedagogia tecnicista", que, ancorada no pressuposto da neutralidade científica e inspirada nos princípios de racionalidade, eficiência e produtividade, "advoga a reordenação do processo educativo de maneira que o torne objetivo e operacional. De modo semelhante ao que ocorreu no trabalho fabril, pretende-se a objetivação do trabalho pedagógico" (SAVIANI, 2007, p. 379).

As metodologias, como definidas pelo IU, são partes da tecnologia que "constituem estratégias de melhoria de resultado", sendo que sua proposta visa à construção de aprendizagem de competências básicas. Essas competências estão relacionadas, conforme a Carta da Superintende do IU, à necessidade de garantir aos alunos do Ensino Médio "[...] o ingresso no mercado de trabalho" (INSTITUTO UNIBANCO 2010, p. 18).

Conforme Saviani (2007, p. 161), sob outra perspectiva, isto é, da formação de um sujeito histórico, do ponto de vista da integralidade, o Ensino Médio utiliza recursos como oficinas com a intenção de que os estudantes dominem "processos práticos básicos da produção", porém isso deve ocorrer de maneira que propicie aos estudantes do Ensino Médio conhecimento dos princípios e das variadas técnicas de produção, e "não mero adestramento em técnicas produtivas".

Quando a concepção de educação passa a ser baseada nos princípios da lógica empresarial, a formação no Ensino Médio fica voltada para inserção dos estudantes no mercado de trabalho, além do fato de as metodologias serem impostas, padronizadas e replicáveis, o 
que entra em contradição com as propostas de uma reestruturação produtiva do capital, as quais propõem que os trabalhadores tenham uma formação criativa, a fim de que possam responder de modo rápido e com habilidade às demandas de raciocínio e que saibam executar trabalhos em equipe.

Entre as características que constituem o PJF, uma proposta em específico se torna preocupante, a de um financiamento por parte do instituto no valor de $\mathrm{R} \$ 100,00$ (cem reais) por aluno, de modo que algumas das redes de escolas públicas aderem ao programa para que possam receber os recursos e, assim, acabam se submetendo às metas "preestabelecidas", que interferem em todo o contexto escolar, desde o conteúdo abordado em sala de aula pelos professores até o conselho escolar.

O alcance das metas do Jovem de Futuro é medido pelo Instituto Unibanco por meio da aplicação de provas. Para as escolas que não conseguirem atingir as metas propostas, o financiamento prometido não é repassado, pois o apoio técnico do Jovem de Futuro é para que as escolas desenvolvam planos de ação, apesar de os recursos serem repassados pelo próprio MEC. Observa-se, assim, que uma empresa pertencente ao terceiro setor atrela os recursos públicos a metas por ele estabelecidas, assim como vincula o recebimento de recursos à premiação, definindo valores mínimos para incentivo aos professores e alunos, tendo em vista os resultados alcançados.

O Programa Jovem de Futuro, ao introduzir suas metodologias no projeto políticopedagógico das escolas públicas estaduais de Ensino Médio, busca apenas alcançar números que viabilizem sua proposta como válida e eficiente, já que não considera a realidade regional e local para a elaboração de propostas educativas que se ajustem a um ideal comum; ao invés disso, lança objetivos e metas para a aprendizagem por meio de uma padronização de métodos. De acordo com Peroni (2012), instituições do setor privado, ao interferirem no sistema de ensino público, elaboram modelos de gestão marcados por desenhos e objetivos prontos, uniformidade no processo, metas e resultados que seguem um padrão geral e não levam em consideração as necessidades e especificidades de cada local.

Observa-se que a concepção que o Instituto Unibanco propõe, influencia a organização do currículo escolar, ao introduzir metodologias de forma padronizada, e assemelha-se ao conceito da "qualidade total" e do fordismo marcado pela produção em série, em grande escala, visando atender às necessidades de consumo em massa.

\section{CONCLUSÕES}

Diante do exposto, os resultados da pesquisa demonstraram que a metodologia proposta pelo Programa Jovem de Futuro do Instituto Unibanco emprega a lógica de mercado nas escolas públicas de Ensino Médio. Ao influenciar a proposta pedagógica das escolas, introduz nas redes estaduais de Ensino Médio metodologias padronizadas e replicadas de maneira uniforme, que não levam em consideração as diferentes realidades, atribuindo ainda o uso de um sistema de monitoramento como forma de controle de resultados, visando formar trabalhadores que atendam às expectativas do setor privado. 


\section{REFERÊNCIAS}

ARAÚJO, Luis César G. Organização, sistemas e as tecnologias de gestão organizacional. 14. ed. São Paulo: Atlas, 2009. v. 1.

BRASIL. Ministério da Educação. Guia de Tecnologias Educacionais 2009. Brasília, DF: Secretaria de Educação Básica, 2009.

BRASIL. Ministério da Educação. Guia de Tecnologias Educacionais 2011/2012. Brasília, DF: Secretaria de Educação Básica, 2011.

BRASIL. Ministério da Administração e Reforma do Estado. Plano Diretor da Reforma do Aparelho do Estado. Brasília, DF: MARE, 1995.

FREITAS, Luiz Carlos de. Os reformadores empresariais da educação: da desmoralização do magistério à destruição do sistema público de educação. Educação \& Sociedade, Campinas, SP, v. 33, n. 119, p. 379-404, abr./jun. 2012. Disponível em: http://www.scielo.br/scielo.php?pid=S010173302012000200004\&script=sci_abstract\&tlng=pt.

FRIGOTTO, Gaudêncio. Os circuitos da história e o balanço da educação no Brasil na primeira década do século XXI. Revista Brasileira de Educação [online], Rio de Janeiro, v. 16 n. 46, p. 235-54, jan./abr. 2011. Disponível em: http://www.scielo.br/scielo.php?pid=S1413-24782011000100013\&script=sci_ abstract\&tlng=pt.

INSTITUTO UNIBANCO. Cardápio de Metodologias Jovem do Futuro - estratégias para implementação do projeto aplicadas a gestores, professores e alunos. 2011. Disponível em: http://www.institutounibanco. org.br. Acesso em: 25 maio 2014.

INSTITUTO UNIBANCO. Relatórios de atividades. 2009, 2010, 2011, 2012. Disponível em: http://www. institutounibanco.org.br/o-instituto/relatorio-de-atividades. Acesso em: 10 maio 2014.

LIMA, Licínio C. Diretor(a) de escola pública: unipessoalidade e concentração do poder no quadro de uma relação subordinada. In: PERONI, V. (Org.). Redefinições das fronteiras entre o público e o privado: implicações para a democratização da educação. Brasília: Liber Livro, 2013.

MAXIMIANO, Antônio Cesar Amaru. Teoria geral da administração: da revolução urbana à revolução digital. 5. ed. São Paulo: Atlas, 2005.

MÉSZÁROS, Istiván. Crise estrutural necessita de mudança estrutural. In: ENCONTRO DE SÃO LÁZARO, 2., 13-17 jun. 2011, Salvador, BA. Conferência de abertura [...]. Salvador: UFBA, 2011.

MONTEIRO, Marcelisa. Relação público-privada na educação básica no Brasil: uma análise da proposta do Instituto Unibanco para o Ensino Médio Público. In: PERONI, V. M. V. (Org.). Redefinições das fronteiras entre o público e privado: implicações para a democratização da educação. Brasília: Liber Livro, 2013.

NEVES, Lucia Maria W. Brasil ano 2000: uma nova divisão de trabalho na educação. 2. ed. São Paulo: Xamã, 2000.

PERONI, Vera Maria Vidal. A gestão democrática da educação em tempos de parceria entre o público e o privado. Pro-Posições, Campinas, SP, v. 23, n. 2 (68), p. 19-31, maio/ago. 2012. Disponível em: http:// www.scielo.br/scielo.php?pid=S0103-73072012000200003\&script=sci_abstract\&tlng=pt. 
PERONI, Vera Maria Vidal. Mudanças no papel do Estado e políticas públicas de educação: notas sobre a relação público/privada. In: PERONI, Vera; ROSSI, Alexandre (Org.). Políticas educacionais em tempos de redefinição do papel no Estado: implicações para a democratização da educação. Porto Alegre: PPGEdu UFRGS; Pelotas: UFPEL, 2011. p. 23-41.

PERONI, Vera Maria Vidal et al. Relação púbico privado na educação básica -notas sobre o histórico e o caso do PDE-PAR- Guia de Tecnologias. Série Estudos - Periódico do Programa de Pós-Graduação em Educação da UCDB, Campo Grande, MS, n. 34, p. 27-44, jul./dez. 2012.

ROBERTSON, Suzan; VERGER, Antoni. A origem das parcerias público-privada na governança global da educação. Educação \& Sociedade, Campinas, SP, v. 33, n. 121, p. 1.133-56, out./dez. 2012. Disponível em: http://www.scielo.br/scielo.php?pid=S0101-73302012000400012\&script=sci_abstract\&tlng=pt.

RODRIGUES, José dos Santos. O moderno príncipe industrial: o pensamento da Confederação Nacional da Indústria. Campinas, SP: Autores Associados, 1998.

SAVIANI, Demerval. Trabalho e educação: fundamentos ontológicos e históricos. Revista Brasileira de Educação, Rio de Janeiro, v. 12, n. 34, p. 152-65, jan./abr. 2007. Disponível em: http://www.scielo.br/ scielo.php?pid=S1413-24782007000100012\&script=sci_abstract\&tlng=pt.

SHIROMA, Eneida Otto; GARCIA, Rosalba Maria Cardoso; CAMPOS, Roselane Fatima. Conversão das "almas" pela liturgia da palavra: uma análise do movimento Todos pela Educação. In: BALL, Stephen J.; MAINARDES, Jefferson (Org.). Políticas educacionais: questões e dilemas. São Paulo: Cortez, 2011.

\section{Sobre a autora:}

Maria Aparecida Canale Balduino: Doutora em Educação pela Universidade Católica Dom Bosco (UCDB). Coordenadora do Curso de Administração da UCDB. E-mail: ccanale@ucdb.br, Orcid: http://orcid.org/0000-0001-8532-9144 
